\title{
Effect of Defect Positions on Fatigue Life Estimation of Stiffened Panel with Profile T and Y using IACS: A Preliminary Study
}

\author{
Firman A. Nugroho, Gorga Notonegoro and Radon Dhelika \\ Department of Mechanical Engineering, Faculty of Engineering, Kampus UI Depok, \\ Universitas Indonesia, 16424 Depok, Indonesia \\ f.adynugroho@gmail.com
}

\begin{abstract}
The defect caused by the transportation and fabrication during oil tanker construction become major concern. Especially, on mid-ship section for the largest cyclic bending moment during the operation. The present research elaborates the fatigue life estimation on stiffened panel with $\mathrm{T}$ and $\mathrm{Y}$ stiffener profile using the IACS CSR. The stress distribution on cross sectional area of stiffened panels with and without defect considered as the preliminary condition for development of fatigue life estimation. The result shows that, the fatigue life estimation of stiffened panel with profile $\mathrm{T}$ and $\mathrm{Y}$ is 34.95 and 35.46 years. The similar the equivalent stress on stiffened panel with profile $\mathrm{T}$ has lower value compared to $\mathrm{Y}$ stiffener profile. The defect positions affect the contour stress distribution of stiffened panels with lower value of equivalent stress compared to the stiffened panel without defect.
\end{abstract}

Key words: Conventional and novel stiffener profiles, cracked stiffened plate, fatigue strength, finite element analysis, mid-ship section, estimation

\section{INTRODUCTION}

The oil tankers are comprised of complex structure on which the stiffeners play important role to strengthen the plate of the hull during operation and the mid-ship section is the area with the largest bending moment for continuous sagging and hogging. Such phenomenon known as fatigue, i.e., the cyclic fluctuating stress on the sub-structure, accumulatively can cause an initiation of crack and furthermore a failure (Hughes and Paik, 2010). Accordingly, the mid-ship section has particular construction in terms directional of working load, i.e., transverse for the lateral load and longitudinal for the axial-compressive load. The deck structure is supported by the typical tee bar, side structures strengthen by angle bar and the bottom structure consist of tee bar, angle bar and flat or bulb bar as stiffeners (Leheta et al., 2015). Various kind of type and position of the stiffener profiles show the importance and the relation toward the load characteristics working on the structure.

Due to the important role of stiffener profiles, especially, on supporting the structural performance under cyclic loading, generated from difference on ship motion and wave pressure (Li et al., 2014) affected by wave height in terms of three degree freedoms $\mathrm{x}$-abscissa, $y$-ordinate and $z$-applicate, i.e., crest and trough of the wave. Continuous sagging and hogging during the operational condition of the ship produce vertical bending load, axial compression, lateral pressure and torsional acting on the sub-structure, i.e., stiffened plate with varied stiffener profiles. Such repeated cyclic stresses accumulatively on sub-structure can end with catastrophic failure in terms of defect on the surface, initiating a crack, crack propagation and failure. The crack happen mostly on the hot spot area, i.e., the intersection on sub-structure carrying load, e.g., bottom, deck and side structure (Fischer and Fricke, 2016) on which supported by varied conventional stiffener profiles. Therefore, fatigue life estimation of the stiffened plate with $\mathrm{T}$ and $\mathrm{Y}$ profile with no defect and with various position of defects in terms of crack on surface should be considered as major concerns.

Accordingly, several related research has been carried out in terms of fatigue analysis of ship structure, for instance (Erny et al., 2012) reported fatigue life prediction of welded ship details. Mahmoud and Riveros (2014) elaborated fatigue reliability of a single stiffened ship hull panel. Tasdemir and Nohut (2012) have investigated the fatigue analysis of ship structure with hinged deck design using finite element analysis, i.e., the primary supporting member of 4900 PCTC. Fricke et al. (2017) conducted fatigue assessment of local stress at fillet welds around plate corners. Yang et al. (2016) carried out the fatigue behavior and strength evaluation of

Corresponding Author: Firman A. Nugroho, Department of Mechanical Engineering, Faculty of Engineering, Kampus UI Depok, Universitas Indonesia, 16424 Depok, Indonesia f.adynugroho@gmail.com 
vertical stiffener welded joint in orthotropic steel decks. Regarding the stiffened plate and the stiffener profile in ship structure (Leheta et al., 2015) have proposed ship structural integrity using new stiffened plate, supported by Badran and El-Kader (2012a, b) that explained about a new fatigue life assessment using alternative stiffened panel in mid ship section and increasing fatigue life in ship structures using Y-stiffeners with right angle of hat.

However, lack of research regarding elaboration on fatigue life assessment according to the stress distribution on the cross sectional area of stiffened plate with novel $\mathrm{Y}$ and conventional $\mathrm{T}$ stiffener profiles using IACS CSR. Especially, on the various positions of defect towards the stress distribution and fatigue life estimation. Furthermore, the defect in terms of initiation of crack could be strong foundation fatigue life assessment equation and the crack propagation. Therefore, on the present researches a sequence of non linier finite element method is conducted on defected and non-defected of stiffened plate with $\mathrm{T}$ and $\mathrm{Y}$ stiffener profile. On which the various positions of defect are considered affecting the cross sectional stress distribution and available life. In addition, cross section of geometrical dimension is considered as constant in all configurations.

\section{MATERIALS AND METHODS}

\section{Referenced stiffened plate and methods}

Oil tanker mid-ship structural characteristics: The object on this present researches is bottom structure of oil tanker mid-ship (Badran et al., 2013), on which comprises of the conventional stiffener profiles, e.g., flat bar, angle bar and tee bar. Figure 1 describes the mid-ship section of the oil tanker on which the stiffener profiles on the inner bottom and deck become the major concerns. The thickness of each stiffeners profile are different from the others on the mid ship structure, e.g., top deck structure, side structure and bottom structure. Therefore, the thickness difference is referred to the classification societies, considered the optimum condition of section modulus of each configuration of the stiffener profiles. Figure 2 shows the conventional $\mathrm{T}$ stiffener profiles geometry which commonly exists in all top, side and bottom structure.

The novel Y stiffener profile is a combination of a hat section flange with the conventional stiffener profiles on the top, fabricated by welding process (El-Hanafi et al., 2013). The geometry of the novel $Y$ stiffener profile considered to replace the conventional one shown in Fig. 3 and 4. Table 1 shows the dimension of the conventional $\mathrm{T}$ and novel $\mathrm{Y}$ stiffener profile. The dimension of novel $\mathrm{Y}$ stiffener profile was designed according to proportionality the weight and the section modulus of the stiffened plate. The stiffened plate with model Y1 is designed with the same section modulus value to the model $\mathrm{T}$ on which generates a lighter mass on

Table 1: Dimension of conventional T (Dimension in $\mathrm{mm}$ )

\begin{tabular}{lcccccc}
\hline $\mathrm{T}$ & $\mathrm{h}_{\mathrm{w}}$ & $\mathrm{t}_{\mathrm{w}}$ & $\mathrm{b}_{\mathrm{f}}$ & $\mathrm{t}_{\mathrm{f}}$ & $\mathrm{b}_{\mathrm{p}}$ & $\mathrm{t}_{\mathrm{p}}$ \\
\hline $\mathrm{T} 1$ & 300 & 12 & 150 & 15 & 850 & 15.5 \\
\hline
\end{tabular}

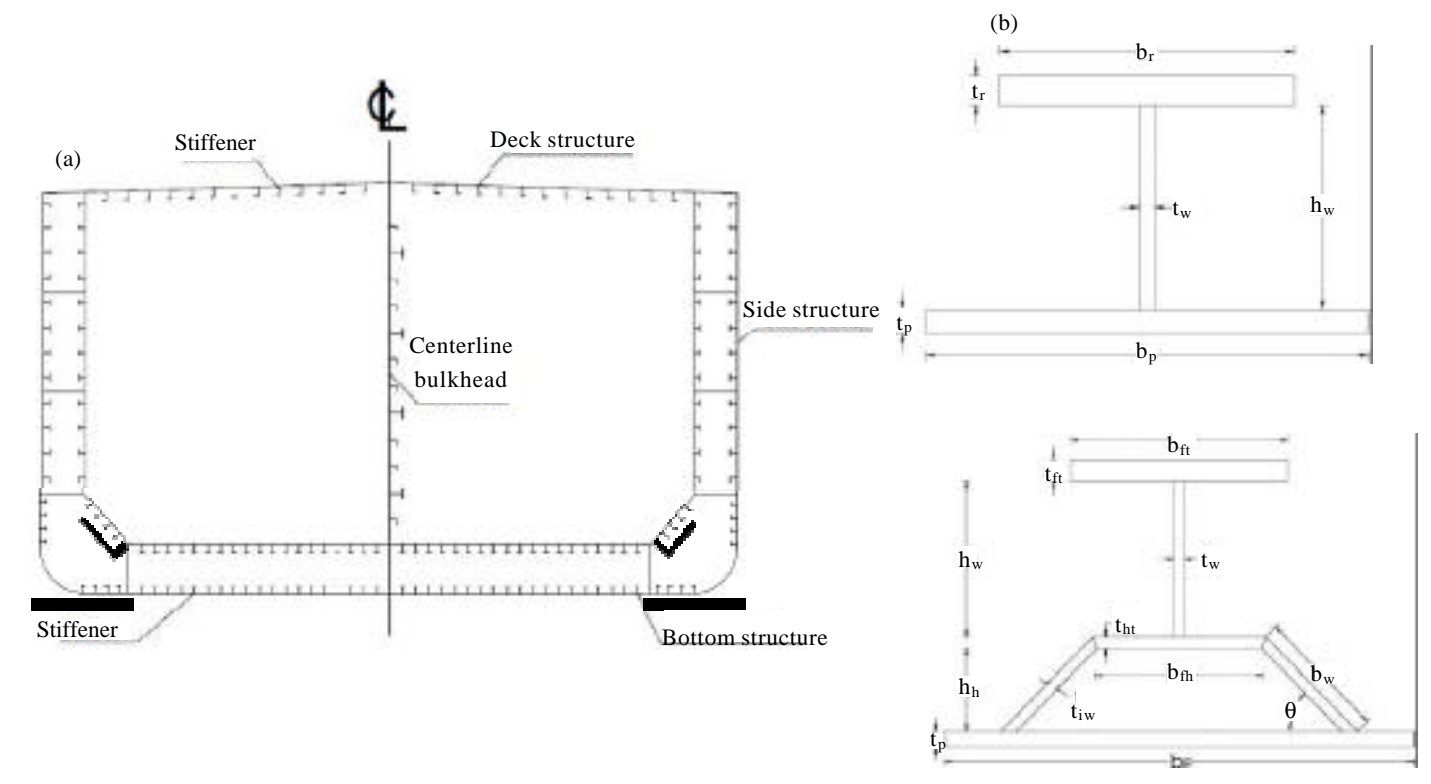

Fig. 1: a) Mid-ship section of oil tanker; b) T stiffener profile and c) Y stiffener profile 
(a)

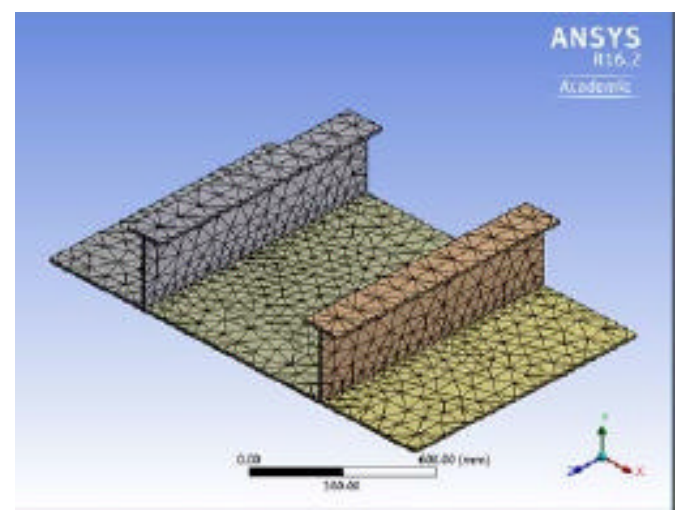

(b)

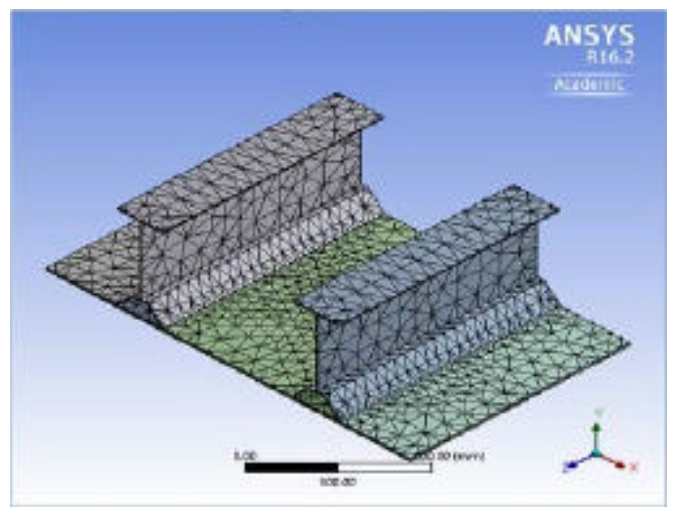

Fig. 2: Meshing on stiffened panel with: a) T and b) Y stiffener profile



Fig. 3: Fixed support of the stiffened panel

Table 2: Dimension of Y stiffener profile

\begin{tabular}{|c|c|c|c|c|c|c|c|c|c|c|c|}
\hline $\mathrm{Y}$ & $\mathrm{h}_{\mathrm{w}}$ & $\mathrm{t}_{\mathrm{w}}$ & $b_{f}$ & $t_{f}$ & $t_{\mathrm{fh}}=\mathrm{t}_{\mathrm{w} w}$ & $b_{\mathrm{fh}}$ & $\mathrm{b}_{\mathrm{iw}}$ & $\mathrm{h}_{\mathrm{h}}$ & $\mathrm{b}_{\mathrm{bh}}$ & $t_{p}$ & $b_{p}$ \\
\hline Y1 & 334 & 5 & 210 & 8 & 9 & 71 & 100 & 66 & 213 & 17 & 850 \\
\hline
\end{tabular}

Model Y1 compared to the Model T. In the other hand, the stiffened plate with the Model Y 2 has the same weight compared to the Model $\mathrm{T}$ resulting higher section modulus value compared to the conventional $\mathrm{T}$ stiffened panel. The correlation among cross sectional geometry characteristic, mass and section modulus explained on Table 2 and 3 .

Non-linear finite element analyses on stiffened panel Finite element model: Previous research has showed promising results in terms of utilization finite analysis, i.e., The utilization of finite element method is to elaborate
Table 3: Section modulus and mass of stiffened plate with $\mathrm{T}$ and $\mathrm{Y}$ stiffener \begin{tabular}{lcc}
\multicolumn{2}{c}{ profile } \\
\hline Models & Mass $(\mathrm{kg})$ & $\mathrm{Z}\left(\mathrm{m}^{3}\right)$ \\
$\mathrm{T} 1$ & 839.66 & 0.0038 \\
$\mathrm{Y} 1$ & 423.83 & 0.0038 \\
\hline
\end{tabular}

comprehensively the elastic-plastic behavior of the stiffened panel. Finite element method is effective in predicting the fatigue strength characteristics of cracked stiffened panel with different configurations of stiffener profiles under cyclic vertical bending load. The simulation using ANSYS 16.2 student version as FEM-based software the covers the variation of position of the 




Fig. 4: Loading on the stiffened panel

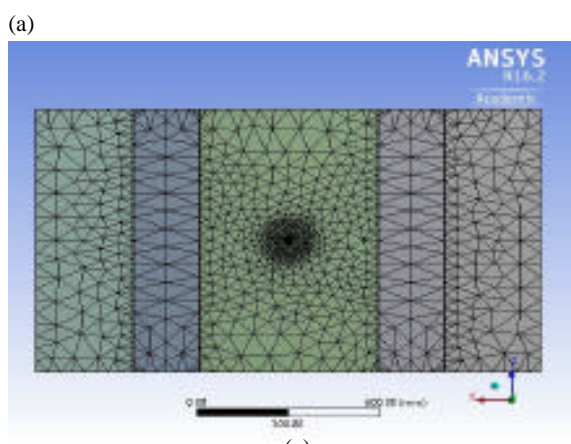

(b)


Fig. 5: a) Defect in the middle; b) Quarter length and c) Adjacent of the stiffeners

semi-elliptical crack on stiffened panel with conventional $\mathrm{T}$ and novel $\mathrm{Y}$ stiffener profiles and the dimension of the stiffener profile for its correlation toward section modulus and mass of the stiffened plate. The estimation of the ultimate strength on thin walled structure composed of plates and stiffeners in terms of box-like structure (Badran et al., 2013). On the finite element analysis, the non-linear behavior of structure is considered with the geometric non-linearity, i.e., large deformation and material non-linearity capabilities in terms of elasticity and yielding (Leheta et al., 2016). The finite element model is used for defected and non-defected stiffened panel with conventional $\mathrm{T}$ and novel $\mathrm{Y}$ stiffener profile. On this study the defect is considered as semi elliptical crack, on which the dimension of the crack is adjusted for the investigation as shown in Table 4 and the positions are varied in lateral direction as shown in Fig. 5a-c, for instance, on stiffened plate with $\mathrm{T}$ stiffener profiles the 
Table 4: Dimension of defect

\begin{tabular}{lccc}
\hline Defect & $\begin{array}{c}\text { Major radius } \\
(\mathrm{mm})\end{array}$ & $\begin{array}{c}\text { Minor radius } \\
(\mathrm{mm})\end{array}$ & $\begin{array}{c}\text { Largest contour } \\
\text { radius }\end{array}$ \\
\hline Semi-elliptical & 5 & 4 & 1 \\
\hline
\end{tabular}

configurations are $\mathrm{T}$ with no-crack, $\mathrm{T}$ middle crack, $\mathrm{T}$ quarter crack and $\mathrm{T}$ adjacent crack. This is in line with the stiffened plate with novel Y profiles where the position of the crack is comprised of $Y$ with no-crack, $Y$ middle crack, $Y$ quarter crack and $Y$ adjacent crack. The stiffened panel with novel $\mathrm{Y}$ stiffener profiles is separated into $\mathrm{Y} 1$ and $\mathrm{Y} 2$, on which the section modulus and mass become consideration compared to the conventional $\mathrm{T}$ stiffener profile.

Figure 2a, $\mathrm{b}$ shows the meshing of stiffened panel with conventional $\mathrm{T}$ stiffener profile and novel $\mathrm{Y}$ stiffener profile. On which the meshing used for the global mesh is the tetrahedron for the compatibility of analysis the crack (Leheta et al., 2016). The global size is coarse in order to conduct fine mesh on the surrounding area of the crack. Fine mesh is created with sphere method of influence with sphere radius $75 \mathrm{~mm}$ and element size is $10 \mathrm{~mm}$.

Load and boundary condition: Loading condition composed of the fixed support and load which is working on. The stiffened panel is designed with the fixed support surrounding of the panel. In the other hand, the uniform load on bottom structure is applied vertically, representing the sagging and hogging during the operational condition. The uniform load used on the stiffened panel is $0.16 \mathrm{MPa}$, representing the wave load received on the bottom structure of the ship during operational condition. Figure 3 shows the fixed support on the stiffened panel with novel Y profile stiffener and the loading is shown in the Fig. 4. The boundary condition consists of the $\mathrm{T}[\mathrm{x}, \mathrm{y}, \mathrm{z}]$ indicating the translational constraints and the $\mathrm{R}[\mathrm{x}, \mathrm{y}, \mathrm{z}]$ indicates rotational constraints in $\mathrm{x}-\mathrm{y}, \mathrm{y}$, $\mathrm{z}$-coordinates, respectively, a " 0 " indicates constraint and a " 1 " indicates no constraint. In accordance with Fig. 4, on which the constraint on the plate nodes area in $\mathrm{Y}, \mathrm{Z}$ and $\mathrm{X}$ direction. On this study, the stiffened panel has parametric constraint $\mathrm{T}[0,1,0]$ and $\mathrm{R}[0,0,1]$ and the deformation in $\mathrm{x}-, \mathrm{y}-, \mathrm{z}-$ from fine mesh section is applied as force boundary condition in stress concentrated model.

Position of defect: The configurations of the position of the semi elliptical crack are with no-crack, in the middle of the stiffeners, quarter length of distance between stiffener and adjacent position. All of those configurations are describe on Fig. 5a-c.
Fatigue life estimation: The fatigue assessment is conducted using International Association Classification Societies Common Structural Rules 2010. It is based on Palmgren-Miner cumulative damage rule and if the cumulative fatigue damage ration is $>1$, structure capability in resisting cyclic loading is not accepted. The focus is on the detailed fatigue life assessment for structure detail in the mid-ship section:

$$
\text { Fatigue life }=\frac{\text { Design life years }}{\mathrm{DM}}
$$

According to the CSR requirements, fatigue life calculation should be more than 25 years:

$$
\mathrm{DM}=\sum_{\mathrm{i}=1}^{2} \mathrm{DMi}
$$

DMI = Cumulative fatigue damage ration for the applicable loading condition

$\mathrm{i}=1=$ For full load condition

$2=$ For normal ballast condition

$$
\mathrm{DMi}=\frac{\alpha_{\mathrm{i}} \mathrm{N}_{\mathrm{L}}}{\mathrm{K}_{2}} \frac{\mathrm{S}_{\mathrm{Ri}}^{\mathrm{m}}}{\left(\operatorname{In} \mathrm{N}_{\mathrm{R}}\right)^{\frac{\mathrm{m}}{\xi}}} \mu_{\mathrm{i}} \Gamma\left(1+\frac{\mathrm{m}}{\xi}\right)
$$

$\alpha_{\mathrm{i}}=$ proportion of the ship's life: $\alpha_{1}=0.5$ for full load condition, $\alpha_{2}=0.5$ for ballast condition $\mathrm{N}_{\mathrm{L}}=$ Number of cycles for the expected design life. Approximate value is between $0.6 \times 10^{8}$ and $0.8 \times 10^{9}$ cycles for 25 years of design life. $\mathrm{f}_{0}=0.85$, factor taking into account non-sailing time for operations such as loading and unloading, repairs, etc. $\mathrm{U}=$ design life $(\mathrm{s})=0.788 \times 109$ for a design life of 25 years, $\mathrm{L}=$ rule length:

$$
\mathrm{N}_{\mathrm{L}}=\frac{\mathrm{f}_{0} \cdot \mathrm{U}}{4 \cdot \log \mathrm{L}}
$$

$\mathrm{K}_{2}=0.63 \times 10^{12} \mathrm{~S}-\mathrm{N}$ curves coefficient as given in CSR (Table C.1.6)

$\mathrm{S}_{\mathrm{ri}}=$ Stress range at the representative probability level of $10^{-4}\left(\mathrm{~N} / \mathrm{mm}^{2}\right)$

$\mathrm{N}_{\mathrm{R}}=10000$, Number of cycles corresponding to the probability level of $10^{-4}$

$\mathrm{m}=\mathrm{S}-\mathrm{N}$ curves exponent as given in CSR (Table C.1.6)

$\xi=$ Weibull shape parameter

$\mu_{\mathrm{i}}=$ Coefficient taking into account the change in the slope of the S-N curve

$\Gamma=$ Gamma function

stress range $s_{R}$, required for the cumulative fatigue damage ratio in Eq. 3 is calculated using simple beam theory: 


$$
\begin{gathered}
\mathrm{S}_{\mathrm{Ri}}=\frac{\mathrm{M}_{\mathrm{Ri}}}{\mathrm{Z}_{\mathrm{v}-\text { net } 75}} \\
\mathrm{M}_{\mathrm{Ri}}=\mathrm{M}_{\mathrm{wv}-\mathrm{hog}}-\mathrm{M}_{\mathrm{wv}-\mathrm{sag}}
\end{gathered}
$$

$M_{R i}$ is the range of wave bending moment at a representative probability level of $10^{-4}$ and $Z_{\mathrm{v} \text {-net75 }}$ is the "net" section modulus (-0.25 tcorr) of the mid-ship cross section.

\section{RESULTS AND DISCUSSION}

Equivalent stress: The output of the simulation considering the variation of position of semi-elliptical crack on the stiffened panel T, Y1 and Y2 in terms of the equivalent stress time curve. Generally, all of the cracked and non-cracked stiffened plates has various pattern of equivalent stress time curves. Figure $6 \mathrm{a}$ shows the equivalent stress of the stiffened panel with conventional $\mathrm{T}$ stiffener profile on which the highest value of equivalent stress is the stiffened plate with adjacent crack, i.e., the closest crack toward the stiffener, following by the crack in the middle of the stiffeners. A significant slope declining of the equivalent time curve happened on the quarter crack between the stiffeners and the lowest value of equivalent stress time is stiffened plate with no crack. The stiffened plate with novel Y1 stiffener profile which has same section modulus and lighter mass compared to the conventional T stiffener profile as shown in Fig. 6b, shows a lower value of equivalent stress in all condition in terms of non-cracked and cracked stiffened panel. The sequence of the details declination values of equivalent stress has similar pattern compared to the stiffened plate with conventional $\mathrm{T}$ stiffener profile, sorted from the highest to the lowest, i.e., Y1 adjacent crack, Y1 middle crack, Y1 quarter crack and no crack. The declination of the equivalent stress value is considered affected by the shape of the novel $\mathrm{Y}$ stiffener in terms of the hat construction on the plate, strengthen in global structure of stiffened plate.

Among the stiffened plates with configuration of stiffener profile, conventional stiffener profile has the lowest equivalent stress for capable of resisting $440 \mathrm{MPa}$ under adjacent crack, i.e., the closest crack to the stiffener. In the other hand, stiffened plate with novel Y1 and Y2 stiffener profile has better equivalent stress compared to the conventional T profile. However, each of novel Y1 and Y2 stiffener profile has equivalent stress on which can only receive $280 \mathrm{MPa}$ of equivalent stress with adjacent crack condition. The crack close to the stiffener become major concern because the geometrical effect of the
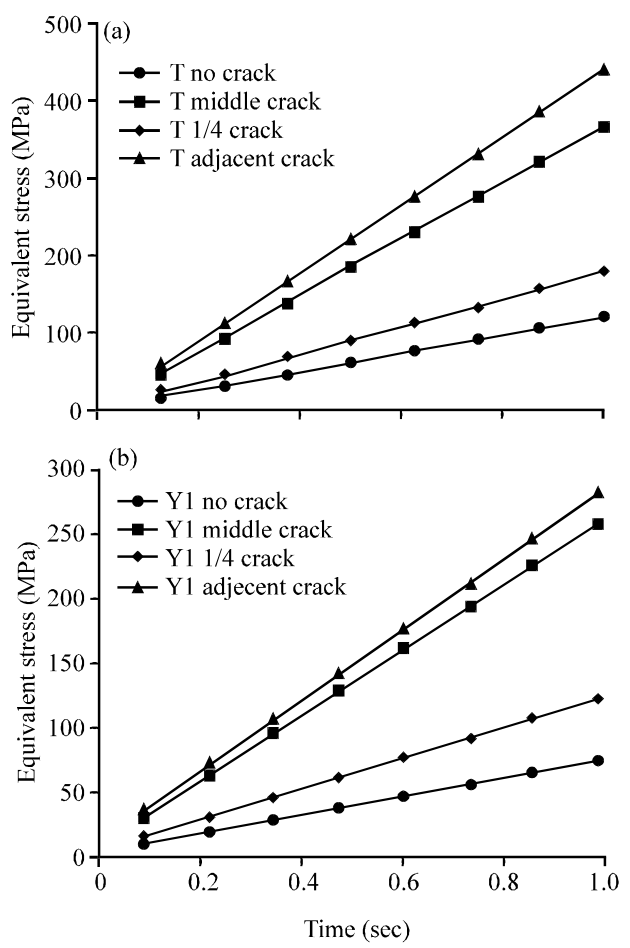

Fig. 6: Equivalent stress time on: a) Pelat $\mathrm{T}$ and b) Pelat $\mathrm{Y} 1$ Out and with defect in 3 positions

stiffened panel affecting the stress distribution surrounding the crack area which further develop in terms of propagation.

Stress distance: On the cross sectional area of the stiffened plate with $\mathrm{T}$ and $\mathrm{Y}$ stiffener profile, equivalent stress distributions are described between the stiffeners in terms of T, Y1 and Y2 profiles with applied particular conditions, i.e. with and without defect on the surface. The $\mathrm{T}, \mathrm{Y} 1$ and $\mathrm{Y} 2$ stiffener profile are adjusted on the geometrical characteristics, section modulus and mass. The defect is the semi elliptical crack in various lateral positions, i.e., middle of the stiffener, quarter length between stiffener and adjacent to the stiffener.

Generally, the stress distribution fluctuation on the cross sectional area of the stiffened plate with profile $\mathrm{T}$ and $\mathrm{Y}$ showed a similar pattern. However, the value equivalent stress and distances in terms of y-axis and in $\mathrm{x}$-axis on both stiffened panel with $\mathrm{T}$ profile and $\mathrm{Y}$ profile showed the different. On which the equivalent stress distribution on the stiffened panel with profile $\mathrm{T}$ is $80 \mathrm{MPa}$ and $54 \mathrm{MPa}$ on the $\mathrm{Y}$ profile as shown in Fig. $7 \mathrm{a}$ and $\mathrm{b}$. In addition, the equivalent stress related to distance shows a shifting on the equivalent stress near by the stiffener on both $\mathrm{T}$ and $\mathrm{Y}$ profile. Such phenomenon is affected by the attached hat construction on the stiffened panel with profile $\mathrm{Y}$. 
(a)

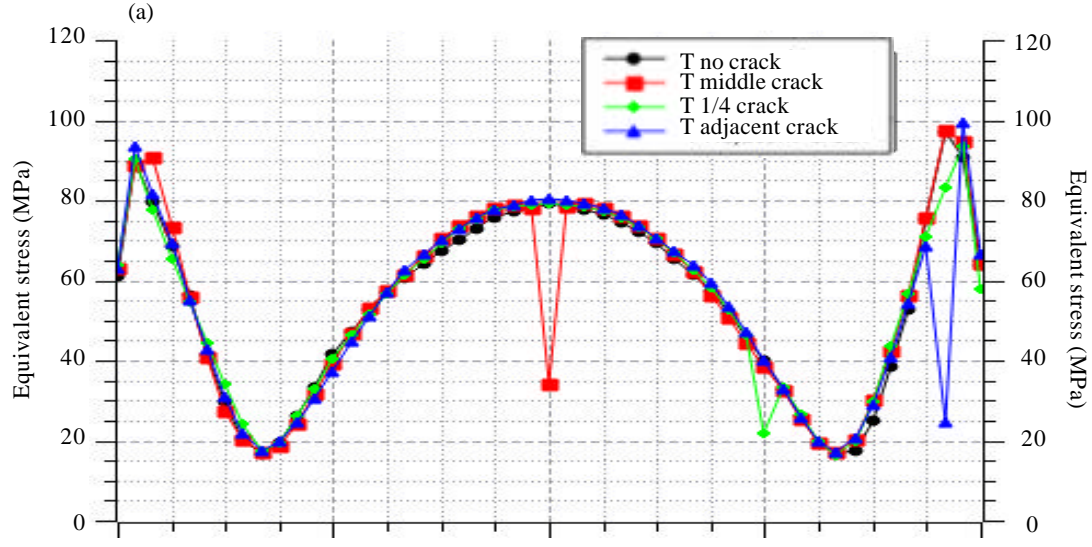

(b)

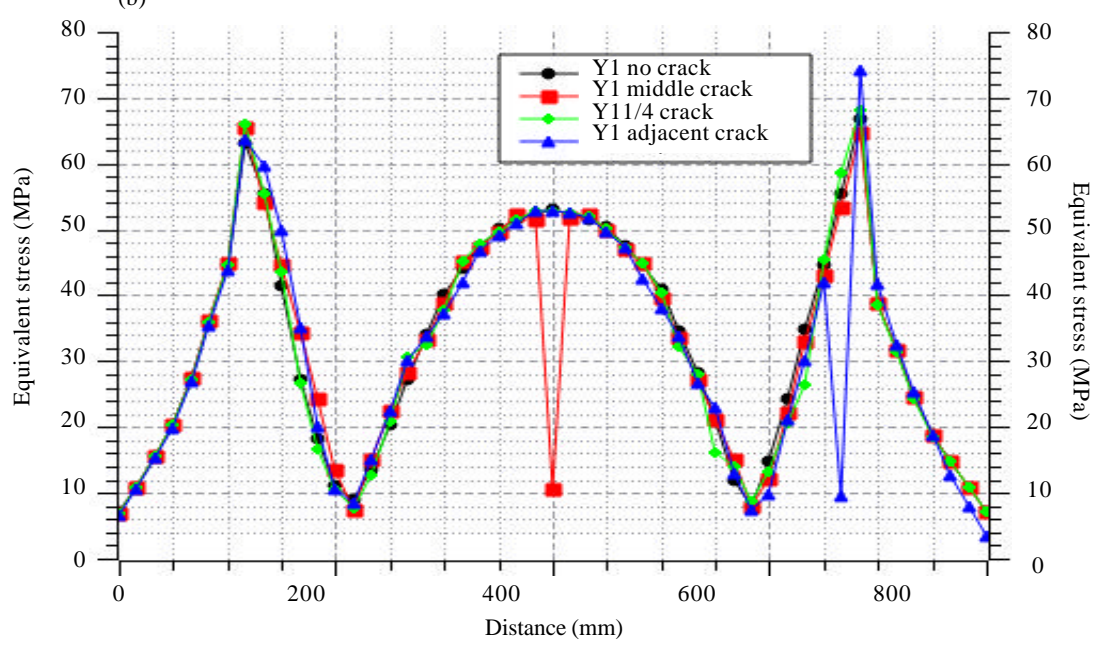

Fig. 7: Stress-distance of stiffened panel with profile: a) Pelat T and b) Pelat Y1

Regarding the effect of defect on various lateral positions on in terms of semi elliptical crack and is comparison to the non-defected stiffened plate. A fluctuation on the equivalent stress distribution along the distance for the defected and non-defected stiffened plate with $\mathrm{T}$ and $\mathrm{Y}$ stiffener profile as shown in Fig. 7. It is affected by the defect, positioned near by the stiffener quarter and middle of the stiffened panel with profile $\mathrm{T}$ and $Y$. The defect in the middle stiffened panel with $Y$ stiffener profile showed lower value of equivalent stress compared to the T stiffener profile. Similar conditions also, happen for others defect positions. This is affected by the additional hat construction, raising the strength of the stiffened plate with $\mathrm{Y}$ stiffener profile compared to $\mathrm{T}$ stiffener profile (Table 5).

Fatigue life prediction: In accordance with the fatigue life, the calculation is carried out with no consideration on effect of defect. Therefore, the calculation consists of the non-defected of stiffened panel with stiffener profile $\mathrm{T}$ and $\mathrm{Y}$ with no defect on surface.
Table 5: Result fatigue life estimation on stiffened panel with profile $\mathrm{T}$ and

\begin{tabular}{lll}
\hline \multicolumn{1}{c}{$\mathrm{Y}$} & Stiffener T & Stiffener Y \\
\hline Rerms & 31.35 & 31.35 \\
Actual section modulus $\left(\mathrm{m}^{3}\right)$ & 34.95 & 35.46 \\
$\mathrm{M}_{\mathrm{w}}(\mathrm{MNm})$ & 3946.65 & 3946.65 \\
$\mathrm{~N}_{\mathrm{L}}$ & 788000000 & 788000000 \\
$\mathrm{~K}_{2}$ & $6.3 \mathrm{E}+11$ & $6.3 \mathrm{E}+11$ \\
$\mathrm{~S}_{\mathrm{Ri}}\left(\mathrm{N} / \mathrm{mm}^{2}\right)$ & 108.48 & 109.24 \\
$\mathrm{M}$ & 3 & 3 \\
$\Xi$ & 0.94 & 0.94 \\
$\mathrm{DM}$ & 0.39 & 0.4 \\
$\mathrm{DM}$ & 0.79 & 0.8 \\
Fatigue life (years) & 28.14 & 29.39 \\
\hline
\end{tabular}

The result shows that the fatigue life of novel $\mathrm{Y}$ stiffened panel with $\mathrm{T}$ and $\mathrm{Y}$ has stiffener profile approximate fatigue life 28.14 and 29.39 years. The similar result of fatigue life, caused by the adjustment on value of section modulus for $Y$ stiffener thus the value is closed to the section modulus of $\mathrm{T}$ stiffener profile. Such condition affects the mass of the $\mathrm{T}$ and $\mathrm{Y}$ stiffener profile on which the stiffened panel with $\mathrm{Y}$ stiffener profile has lighter mass compared to the stiffened panel with $\mathrm{T}$ stiffener profile. 


\section{CONCLUSION}

The objectives of this study is to conduct a preliminary study on the development of the fatigue life formulation referred to IACS CSR rules, i.e., elaboration the effect of lateral defect positions on both stiffened panel with $\mathrm{T}$ and $\mathrm{Y}$ stiffener profile, in terms of the equivalent stress-distance using numerical approach and the fatigue life estimation on non-defect conditions of stiffened panel using IACS CSR Rules. Accordingly, a series of non-linier finite element method computations were conducted. The variable comprises of defect positions, geometrical dimension of stiffener $\mathrm{T}$ and $\mathrm{Y}$, section modulus, mass and the fatigue life.

Based on the results obtained from the present works, the conclusions can be described as follows: stiffened panel with profile $Y$ has lower value of equivalent stress compared to the stiffened panel with profile $\mathrm{T}$. The hat on the panel play important role in strengthening the panel, the defect increases the equivalent stress on stiffened panels, on which the stiffened panel with $\mathrm{T}$ has higher value compared to the and $\mathrm{Y}$ stiffener profile, on the cross sectional area, stiffened panel with $\mathrm{Y}$ has relatively lower the stress distribution compared to the stiffened panel with $\mathrm{T}$ profile, the defect also affect the stress distribution on lateral condition. The result from numerical approach of effect of defect on stiffened panels will be used as foundation to develop the fatigue strength equation in IACS in terms of elaboration on the gamma function.

\section{ACKNOWLEDGEMENT}

A preliminary study of defect positions on fatigue life estimation of conventional and novel stiffened panel with profile $\mathrm{T}$ and $\mathrm{Y}$ using IACS CSR and numerical approach is conducted as part of the requirement of being permanent lecturer at the Universitas Indonesia. The researcher wish to thanks Dr. Agus S. Pamitran who give valuable inputs on writing assistance of the study as well as the others member who contribute in calculations.

\section{REFERENCES}

Badran, S.F. and M.A.A. El-Kader, 2012b. A new quantitative fatigue life assessment using alternative stiffened panels in midship section. Eur. J. Sci. Res., 90: 473-492.

Badran, S.F. and M.A.A. El-Kader, 2012a. Increasing fatigue life in ship structures using Y-stiffeners with right angle of hat. Eur. J. Sci. Res., 91: 364-380.
Badran, S.F., A.B. Saddek and H.W. Leheta, 2013. Ultimate strength of $\mathrm{Y}$ and $\mathrm{T}$ stiffeners subjected to lateral loads with three different levels of initial imperfection. Ocean Eng., 61: 12-25.

El-Hanafi, A.S., S.F. Badran and H.W. Leheta, 2013. Design of Y Stiffened Panels in Double Hull Tanker Under Axial Compressive Loads. In: Analysis and Design of Marine Structures, Soares, G. and J. Romanoff (Eds.). CRC Press, Boca Raton, Florida, USA., pp: 291-300.

Erny, C., D. Thevenet, J.Y. Cognard and M. Korner, 2012. Fatigue life prediction of welded ship details. Mar. Struct., 25: 13-32.

Fischer, C. and W. Fricke, 2016. Effect of the stress distribution in simple welded specimens and complex components on the crack propagation life. Intl. J. Fatigue, 92: 488-498.

Fricke, W., L. Gao and H. Paetzold, 2017. Fatigue assessment of local stresses at fillet welds around plate corners. Intl. J. Fatigue, 101: 169-176.

Hughes, O.F. and J.K. Paik, 2010. Ship Structural Analysis and Design. Society of Naval Architects and Marine, New Jersey, USA., ISBN:9780939773824,

Leheta, H.W., A.S. Elhanafi and S.F. Badran, 2016. A numerical study of the ultimate strength of Y-deck panels under longitudinal in-plane compression. Thin Walled Struct., 100: 134-146.

Leheta, H.W., S.F. Badran and A.S. Elhanafi, 2015. Ship structural integrity using new stiffened plates. Thin Walled Struct., 94: 545-561.

Li, Z., W. Mao, J.W. Ringsberg, E. Johnson and G. Storhaug, 2014. A comparative study of fatigue assessments of container ship structures using various direct calculation approaches. Ocean Eng., 82: 65-74.

Mahmoud, H. and G. Riveros, 2014. Fatigue reliability of a single stiffened ship hull panel. Eng. Struct., 66: 89-99.

Tasdemir, A. and S. Nohut, 2012. Fatigue analysis of ship structures with hinged deck design by finite element method: A case study: Fatigue analysis of the primary supporting members of 4900 PCTC. Mar. Struct., 25: 1-12.

Yang, M., B. Ji, Z. YuanZhou and Z. Fu, 2016. Fatigue behavior and strength evaluation of vertical stiffener welded joint in orthotropic steel decks. Eng. Fail. Anal., 70: 222-236. 